\title{
Why Managers Should Care About Fairness: The Effects of Aggregate Justice Perceptions on Organizational Outcomes
}

Tony Simons and Quinetta Roberson Cornell University

This work examines the aggregation of justice perceptions to the departmental level and the business-unit level, the impact of these aggregate perceptions on businessunit-level outcomes, and the usefulness of the distinction between procedural and interpersonal justice at different levels of analysis. Latent variables analyses of individual-level and department-level data from 4,539 employees in 783 departments at 97 hotel properties showed that the 2 justice types exercise unique paths of impact on employees' organizational commitment and thus on turnover intentions and discretionary service behavior. Business-unit-level analyses further demonstrate paths of association between aggregate justice perceptions, aggregate commitment levels, and the business-unit-level outcomes of employee turnover rates and customer satisfaction ratings. 
The study of organizational justice has emerged as an extremely popular topic in industrial-organizational psychology, human re- source management, and organizational behavior (Colquitt, Conlon, Wesson, Porter, \& Ng, 2001; Cropanzano \& Greenberg, 1997; Greenberg, 1990). Organizational justice research, which focuses on the role of fairness as a consideration in the workplace, has demonstrated that fair treatment has important effects on individual employee attitudes, such as satisfaction and commitment, and individual behaviors, such as absenteeism and citizenship behavior (Colquitt et al., 2001). In addition, research has demonstrated associations between perceived justice and individual work performance (Cohen-Charash \& Spector, 2001; Colquitt et al., 2001).

Greenberg and Lind (2000) have noted that most existing justice research has been "designed primarily to inform theory development, and only secondarily, organizational practice" (p. 73). Much of the research in this area has centered on the formation of justice perceptions, specifically on perceptual determinants of fairness or unfairness, and subsequent individual cognitive and attitudinal reactions. Although researchers may draw implicit relationships between individual-level and higher level outcomes (e.g., higher levels of employee satisfaction from perceptions of procedural justice should lead to lower turnover rates in organizations), we have found no published studies that empirically demonstrate a clear link between perceptions of fairness and organizationlevel or business-unit-level operational outcomes. We believe that the study of justice at higher levels of analysis and business-unit-level consequences of justice may better inform organizational practice. Thus, we examine such higher level relationships in this study.

Most of the critical outcomes to which senior managers attend-for example, revenues, profitability, customer satisfaction-emerge at the group, business-unit, or organizational level, as these levels reflect the scope of the managers' authority. To establish a link between fairness and organizational outcomes, we must con- sider the operation of fairness perceptions at the organizational level. As described by Kozlowski and Klein (2000), "many phenomena in organizations have their theoretical foundation in the cognition, affect, behavior, and characteristics of individuals, which-through social interaction, exchange, and amplification-have emergent properties that manifest at higher levels" (p. 15).

The purpose of this study is to explore the effects of collective procedural and interpersonal justice perceptions on organization- level outcomes. First, we build theoretical arguments as to why aggregate fairness perceptions represent a viable conceptual focus and why they should affect organizational outcomes. Second, we develop and test hypothesized relationships between employees' collective fairness perceptions and the organizational-level outcomes of employee turnover and customer satisfaction. Building on established individual-level relationships between fairness and employee attitudes and behavior, we show that individual justice perceptions combine 
to reflect and shape justice climates and that these climates affect organizational outcomes. Along the way, we examine the distinction between procedural and interpersonal justice and the unique paths of impact of these two justice types at different levels of analysis.

Literature Review

\section{Organizational Justice}

Thibaut and Walker's (1975) research on individuals' reactions to dispute resolution procedures led to the development of procedural justice theory, which is concerned with judgments about the process or means by which allocation decisions are made. $\mathrm{Re}$ - searchers have offered several different typologies for and operationalizations of procedural justice (Leventhal, 1980; Thibaut \& Walker, 1975). Research in this area has shown that the fairness of decision-making policies and practices is an important consideration for individuals.

Research has further highlighted the importance of interactional justice, or the quality of interpersonal treatment received during the implementation of decision-making procedures. On the basis of a qualitative study of treatment expectations in a corporate recruitment setting, Bies and Moag (1986) identified four criteria for fair interpersonal treatment. They proposed that the fairness of interpersonal treatment is evaluated on the basis of the extent to which decision-making authorities are truthful, respectful, and consider- ate in communicating decisions and the extent to which they justify or explain the rationale for decisions. Interactional justice perceptions may be understood as evaluations regarding the informational and interpersonal components of decision makers' behavior in communicating decisions (Greenberg, 1993).

Cropanzano and Greenberg (1997) asserted that allocation decision-making processes include aspects of both procedural and interactional justice. For this reason, they expect an association between the two. However, research has highlighted differences between these constructs. For example, Masterson, Lewis, Goldman, and Taylor (2000) found empirical evidence that the two justice types are not only distinguishable but have different con- sequences, with procedural justice operating primarily through the mediation of perceived organizational support and interactional justice operating primarily through the mediation of leader-member exchange. Furthermore, drawing on the differentiation of informational and interpersonal aspects of interactional justice, Colquitt and colleagues (Colquitt, 2001; Colquitt et al., 2001) found evidence of empirical distinguishability and of distinct con- sequences for the procedural, interpersonal, and informational aspects of justice. As a growing body of research supports the differential effects of procedural justice and interpersonal justice, we explore their separate impacts on organizational-level outcomes in this study.

In a recent review of the procedural justice literature, Konovsky (2000) noted the almost complete absence of higher order and multilevel analyses of organizational 
justice. However, a few researchers have begun to examine fairness at a higher level of analysis. For example, in a study of procedural justice as a contextual variable, Mossholder and his colleagues (Mossholder, Bennett, \& Martin, 1998) explored justice perceptions within and among organizational work units at a financial services organization. Their study examined whether employees belonging to the same work unit shared perceptions of procedural justice and whether a work unit measure of organizational fairness was associated with employee reports of job satisfaction and organizational commitment. The results showed significant within-unit agreement and between-unit variation in the procedural justice measure. In addition, the findings demonstrated that individuals belonging to units with higher aggregate perceptions of procedural justice reported greater job satisfaction than would have been expected on the basis of their individual justice perceptions alone. Overall, the results of this study suggest that a collective assessment of fair treatment by an organization may exist among individual work group members and that these collective perceptions account for unique variance in important outcomes.

In a more recent study of fairness at the group level, Naumann and Bennett (2000) introduced the concept of "procedural justice climate," which is a group-level cognition about how a work group as a whole is treated. Interrater agreement indexes demonstrated high levels of consensus among members of work groups on these fairness perceptions. In addition, the results of cross-level analyses showed that aggregate procedural justice perceptions explained unique variance in behavior beyond that predicted by individual procedural justice perceptions. Because procedural justice climate, as conceived by Naumann and Bennett, focuses on perceptions of how fairly the work group is treated, it is a different construct than is generated by the simple aggregation of individual procedural justice perceptions. However, the two constructs are conceptually and operationally similar.

Overall, the results of these studies suggest that shared perceptions of organizational environments, that is climates, exist with regard to the fairness of policies and procedures. Furthermore, they support the aggregation of justice perceptions to the group level. Although these studies extend the study of fairness to a higher level of analysis, they focus primarily on the work group. We propose that higher levels of aggregation of justice perceptions - to the business-unit level-are conceptually and practically meaningful. They are conceptually meaningful because they rep- resent an element of experience that is shared among employees at a given workplace. They are practically meaningful because they allow for the examination of the business-unit-level consequences of managerial conduct.

Collective justice perceptions at the work group or department level may be understood to emerge from several sources. First, climates are likely to develop in work units in which employees experience the same manager and/or similar work rules and procedures (Schneider \& Reichers, 1983). Although it is plausible that interactions between supervisors and individual employees may differ, research suggests that work 
units progress toward interpersonal homogeneity such that the treatment of one group member is extended to the rest of the group given common goals and similar interests (Schneider, 1987). Second, the cultural standards that employees apply to assess fairness are likely, to some extent, to be shared by employees who share geographic, professional, educational, ethnic, or other demographic attributes, as such commonalities highlight similarities in interests, which encourage members to depersonalize their experiences and focus on the group. Third, fairness perceptions are likely to be primed and amplified by social information processing as people discuss their experiences and their fairness judgments regarding those experiences (see Lind, Kray, \& Thompson, 1998).

At the business-unit or organizational level, however, additional mechanisms come into play. Although the broader set of employees respond to a broader group of managers' conduct, it is likely that some behavioral norms develop among managers at a single organization, especially to the extent that the managers interact in cross-departmental meetings and ultimately report to the same executive. Furthermore, the various managers often apply a fairly uniform set of procedures and policies across the organization, and these also affect justice perceptions. In addition, social interaction, although less intensive than at the work group level, can still serve the functions of perceptual priming and amplification among employees, as rumors and organizational stories shape employee expectations and often take on their own momentum. Finally, structural attributes of a given company or business unit have been shown to affect employee justice perceptions (Schminke, Ambrose, \& Cropanzano, 2000).

\section{Climate Research}

Organizational climate has traditionally been described as a set of shared perceptions of policies, practices, and procedures that an organization rewards and supports (James, Joyce, \& Slocum, 1988; Schneider \& Reichers, 1983). As such policies and practices are considered to be objective properties of organizations, climate indicates what goals are important to the organization and how such goals are to be accomplished (Schneider, Brief, \& Guzzo, 1996). Properties of an organization have the effect of creating similar organizational experiences for employees of the organization. In other words, employees who are subject to the same policies and procedures in organizations may have shared interpretations of such practices. Thus, consistent perceptions and meanings manifest themselves as climates in organizations (Schneider \& Reichers, 1983).

Climate scholars have explored climate at the organizational level, which is represented by aggregated individual perceptions of organizational events and practices (James \& Jones, 1974). Rather than focusing on individual psychological representations of work situations, organizational climates signify collective meanings that people attach to particular characteristics of the organization. Consequently, organizations tend to have climates for specific elements of the work setting, for example, climate for service 
(Schneider, Parkington, \& Buxton, 1980) and climate for safety (Zohar, 1980). As climates are, by definition, characterized by shared perceptions of organizational policies, practices, and procedures, organizations may also have climates for fairness. We explore such climates for fairness in this study.

Our study has three objectives. First, in an answer to Konovsky's (2000) call for justice research at higher levels of analysis, we explore the existence of collective perceptions of fairness in organizations. More specifically, we examine the existence of justice climates at the departmental and organizational levels of analysis. As research supports the differential effects of procedural and interpersonal justice on individual outcomes (see, e.g., Bies, 2000; Colquitt, 2001; Colquitt et al., 2001; Masterson et al., 2000), the second objective of our study is to investigate the differential effects of shared perceptions of procedural and inter- personal justice at the departmental and organizational levels. Although empirical evidence shows that aggregate fairness perceptions explain unique variance in attitudes and behaviors (Moss- holder et al., 1998; Naumann \& Bennett, 2000), few, if any, studies have explored the relationship between fairness and organizational-level operational outcomes that are of concern to executives. Therefore, consistent with a recent call by Greenberg and Lind (2000) for an increase in the practical value of organizational justice studies, our third contribution is an attempt to link organizational fairness to objective organizational outcomes in this study. More specifically, we build a relationship between aggregate fairness perceptions, behavior patterns, and the organizational outcomes of employee turnover and customer satisfaction.

\section{Hypotheses}

Organizational justice research has shown consistent relation- ships between perceptions of fairness and various individual work outcomes. According to the group value model of procedural justice, fair procedures are believed to affirm an individual's status in a group, thereby strengthening that individual's level of identification with, and attachment to, the group (Lind \& Tyler, 1988). Similarly, because fair organizational processes are more likely to protect and/or promote an individual's interests in an organization, such processes should enhance the degree of attachment to the organization (Konovsky, Folger, \& Cropanzano, 1987). Organizational justice studies have shown that perceptions of procedural fairness strengthen individuals' commitment to the organization as a whole (Brockner, DeWitt, Grover, \& Reed, 1990; McFarlin \& Sweeney, 1992).

A relationship between interpersonal justice and commitment should also exist, but this relationship may be indirect. Some evidence can be drawn from studies of the broader construct of interactional justice. Konovsky and Cropanzano (1991), in a study of the perceived fairness of employee drug testing, found that employees' affective organizational commitment was significantly related to the explanations decision makers offered about the drug testing procedure. Similarly, Barling and Phillips (1993) found, in 
a vignette study of students, that interactional justice influenced organizational commitment. More recent research in this area provides evidence that procedural justice affects attitudes about the company through perceived organizational support whereas interactional justice affects attitudes about the supervisor through leadermember exchange (Masterson et al., 2000). Colquitt (2001) hypothesized and found a clear association between interpersonal justice and leader evaluations. Because most employees tend to view their supervisor as a key representative of the organization, we expect that interpersonal justice is associated with organizational commitment and that this association is mediated by employee attitudes about their supervisor.

Consistent with existing empirical and theoretic work, we expect interpersonal and procedural justice perceptions to be strongly associated with each other. A metaanalysis by Colquitt et al. (2001), with a total sample of approximately 3,000 subjects, found a corrected correlation of $r .63$ between the two constructs. Interactional justice has been conceived as an element or subset of procedural justice (Niehoff \& Moorman, 1993; Tyler \& Bies, 1990), and procedures that are presented in a considerate fashion are more likely to be accepted as fair (Bies \& Moag, 1986). However, one might also argue for the reverse causal direction, as the fact that managers are asked to communicate and enforce perceived unfair policies might affect perceptions of their interpersonal conduct-or interpersonal justice. Rather than proposing and testing a causal direction, which is beyond the focus of this study, we simply anticipated a correlation between interpersonal justice and procedural justice.

The relationships between both justice types and employee commitment readily translate to the organizational level. Organizational policies and procedures may form shared bases for employees' procedural justice perceptions, and managers' behavioral norms may form a shared basis for employees' interpersonal justice perceptions (Schminke et al., 2000). These shared justice perceptions, in turn, may create a climate that promotes or inhibits positive attitudes toward supervision and employee affective commitment to the organization. Employee social norms can either endorse or vilify displays of employee satisfaction with supervision and caring for the company. As was argued at the individual level, we can expect satisfaction with supervision to mediate the impact of interpersonal justice on organization commitment.

The impact of employee affective commitment on turnover intentions and turnover, as a causal sequence, has been extremely well documented in several studies, literature reviews, and meta-analyses (see, e.g., Cohen, 1993; Jaros, Jermier, Koehler, \& Sincich, 1993; Tett \& Meyer, 1993). This impact emerges from both definitional and causal mechanisms: First, the experience of loyalty and a desire to stay with the company are generally considered to be a definitional element of the affective organizational commitment construct itself (Jaros et al., 1993; Mowday, Steers, \& Porter, 1979). Second, affective commitment to the organization is generally conceived to also include identification with the organization and willingness to expend extra effort on its behalf. It is reasonable to expect that such a level of caring stimulates a desire to remain with 
the company, in part because a committed employee may have a dedicated interest in helping the organization to succeed. Although the association between commitment and intent to remain with the company (or, conversely, turnover intentions) derives in part from conceptual overlap, it is well demonstrated that commitment does influence employee turnover and that this impact is mediated by turnover intentions.

Employees' commitment to the organization may also be expected to affect employees' service behavior. Models by Scholl (1981) and Weiner (1982) have provided theoretical support for a commitment-organizational citizenship behavior (OCB) relationship. Both models suggest that commitment maintains behavioral direction when behaviors do not depend on reward or punishment. Furthermore, commitment drives prosocial behaviors that indicate a personal concern with the organization or that reflect personal sacrifice made for the sake of the organization. O'Reilly and Chatman (1986) found, in a study of university employees, that identification and involvement were significant predictors of extra-role compliance behaviors. Shore and Wayne (1993) found that affective commitment predicted both altruistic and compliance organizational citizenship behaviors in a multinational firm. The link between affective organizational commitment and citizenship behaviors is well documented by the studies noted above.

Theory suggests that the behaviors that comprise citizenship are likely to be quite different depending on the actual role requirements of the job (Van Dyne, Cummings, \& McLean Parks, 1995) and that the context of the job determines which of these behaviors are discretionary (McLean Parks \& Kidder, 1994). In service industries, employees' going out of their way to accommodate customer requests may be particularly important for organizational performance, as such behavior is likely to affect customer satisfaction and repeat business. Blancero and Johnson (1997) proposed discretionary service behaviors (DSBs) as a subset of OCB that focuses on the customer-employee interaction. DSBs are defined as those behaviors in which employees go beyond formal job requirements to please guests or customers. We expect employees' affective organizational commitment to affect their willingness to expend discretionary effort to serve their companies' service goals (Hosmer, 1994), and we expect this discretionary effort to result in greater customer satisfaction. We also expect affective commitment to exert a direct impact on guest service satisfaction, as employee affective commitment may be expected to affect effort expenditure and affective tone in ways that are not, strictly speaking, beyond the formal requirements of hospitality jobs. In essence, we expect committed service employees to do their jobs better and to show willingness to exceed the boundaries of their jobs. Likewise, norms of commitment should be associated with shared expectations of service beyond formal job definitions and of high personal job performance.

The hypothesized relationships in this study are shown in Figure 1. Given the relationships established at the individual level, we hypothesize similar relationships among aggregated constructs at the departmental and organizational levels of analysis. However, given that climate perceptions represent meaning derived from the 
organizational context and form the basis for individual and collective responses (Schneider \& Reichers, 1983), we hypothesize that aggregate justice perceptions affect objective organizational outcomes. More specifically, as exposure to similar organizational policies and practices as well as social interaction encourages the development of collective climate perceptions, organizational- level justice perceptions may influence operational measures, such as annual employee turnover rates and customer satisfaction. To examine the process through which justice might affect such organizational outcomes, we explore this link through multiple mediated relationships.

\section{Method}

\section{Sample and Procedures}

Employee survey data were originally collected from 111 different hotel properties in the United States and Canada run by a single large hotel management company. Surveys were administered by the Employee Services Department and offered to all 13,239 employees during company time at each of the hotel locations. The questionnaire was administered on site in employee meetings. Participation was encouraged in part by a raffle for small prizes, such as sweatshirts and free dining coupons. The response rate was $67 \%$, with a total of 8,832 completed surveys returned. The hotels ranged in size from 15 to 505 employees, with an average of 118.7 employees. Annual room revenues averaged approximately $\$ 5.4$ million and ranged from approximately $\$ 1$ million to $\$ 25.8$ million.

One hundred one of the hotel properties provided employee turnover rates. Of these, three hotel properties showed either increases or decreases in their total employee base of greater than $40 \%$ during the period studied, and their employee turnover rates were thus considered to be unrepresentative of the relative equilibrium presumed by cross-

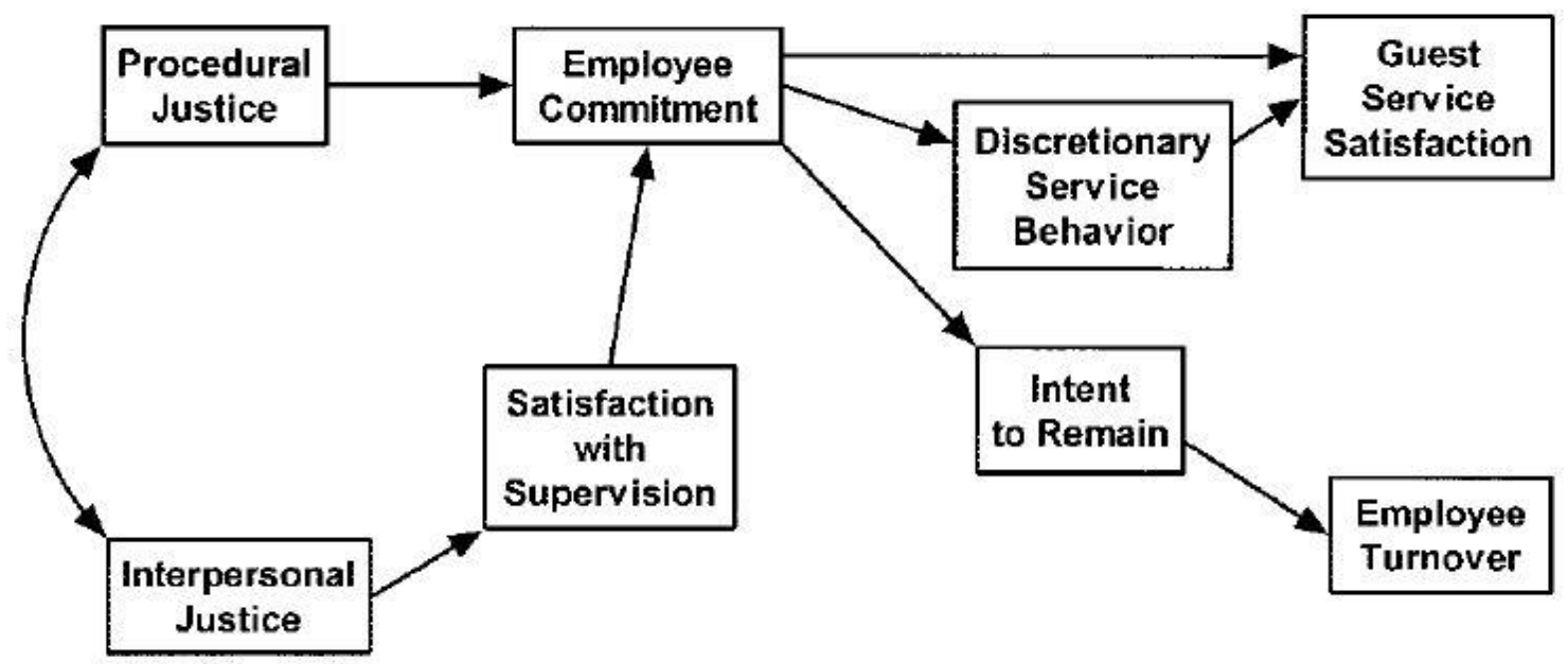

Figure 1. Proposed model predicting employee turnover and customer service from justice perceptions. 
sectional study. Thus, a total sample of 98 hotels was used to assess hypotheses regarding employee turnover. Eighty-four of the hotel properties used a standardized method of measuring customer satisfaction (those hotels that carried a particular brand franchise), and the data from these hotels were analyzed for hypotheses that focused on customer or guest satisfaction. The two data samples overlapped; all of the initial 111 hotel properties provided data that were used in one or both of the hypothesis tests.

Table 1

Rotated Pattern Matrix for Exploratory Factor Analysis of Justice Scale Items

\begin{tabular}{lrr}
\hline & \multicolumn{1}{c}{ Factor loading } \\
\cline { 2 - 3 } Item & \multicolumn{1}{c}{ PJ } \\
\hline When hotel management staff make decisions about my job, they ... & & \\
$\ldots$ are sensitive to my personal needs. & .85 & .01 \\
$\ldots$ show concern for my rights as an employee. & .84 & .07 \\
$\ldots$ deal with me honestly. & .84 & .05 \\
$\ldots$ treat me with kindness. & -.10 & .06 \\
Employees can challenge or appeal management decisions. & .10 & .88 \\
Hotel management staff hear all employee concerns before they make & .79 \\
job decisions. & .11 & .75 \\
To make decisions about our jobs, hotel management staff collect & & \\
good information. & & \\
\hline
\end{tabular}

Note. $\mathrm{IJ}=$ interpersonal justice; $\mathrm{PJ}=$ procedural justice.

Fifty-one percent of the respondents indicated that they were female and $38 \%$ identified themselves as male, with the remainder unspecified. In terms of ethnicity, 19\% indicated they were African American, 1\% American Indian, 8\% Asian American or Pacific Islander, 31\% Caucasian, and 23\% Hispanic. Fourteen percent of the respondents identified themselves as managers. The median age of the respondents was between 35 and 40 years of age, with $78 \%$ indicating that they were full-time regular employees. Fourteen percent of the employees reported having only a grade-school education, $13 \%$ reported some high school, $31 \%$ reported a high school diploma, and $42 \%$ reported education beyond high school. Seventy-five percent of the surveys were administered in English and 23\% in Spanish, with the balance of the questionnaires in Chinese, Creole French, and Vietnamese. The questionnaires were translated into each of these languages following standard translation-back translation procedures and were individually pilot-tested. In addition, an attempt was made to query illiterate employees by offering a "read aloud" table at all survey administrations, where an employee services manager from another property talked illiterate employees through the survey-approximately $7 \%$ of the employees availed themselves of this opportunity. These percentages (demographics, languages, and methods) did not substantially differ between the smaller and larger data subsets used in this study. Although the survey data are cross-sectional, the sequence of data gathering activities approximated a temporally lagged data set. In other words, employee surveys were distributed and collected during the last week of January 1999, guest satisfaction scores 
were tallied from the 4 months between January and April 1999, and employee turnover rates were tallied from the 6 months from January to July 1999.

\section{Measurement of Key Constructs}

Justice perceptions. Procedural justice (PJ) and interpersonal justice (IJ) were measured using scales based on Niehoff and Moorman (1993). Because of the evident grammatical complexity of the original scale items, we used Microsoft Word software to assess their readability and came out with a reading level above 11th grade. Our sample population required something below a 6th-grade reading level, and so, in consultation with Niehoff, we simplified the language. We ended up with a three-item scale measuring PJ $(a \alpha=.78)$ and a four-item scale measuring IJ $(\alpha=.89) .1$ Scale items, shown on Table 1, are similar to those proposed by Colquitt (2001). PJ and IJ scale reliabilities were found to be strong for most of the linguistic and format permutations offered: read-aloud format ( $n=475 ; \mathrm{PJ} \alpha=.79, \mathrm{IJ} \alpha=.87)$, English ( $n=$ 4,271; PJ $\alpha=.77$, IJ $\alpha=.89)$, Spanish ( $n=1,650 ; \mathrm{PJ} \alpha=.79$, IJ $\alpha=.90)$, Chinese $(n$ $=37 ; \mathrm{PJ} \alpha=.56$, IJ $\alpha=.87)$, Vietnamese ( $n=22 ; \mathrm{PJ} \alpha=.89$, IJ $\alpha=.93)$, and Creole French ( $n=14$; PJ $\alpha=.61$, IJ $a=.91)$. It is important to note that reliabilities were weak for the PJ measure in Chinese and in Creole French. However, these potential problems affected only a very small segment (less than $1 \%$ ) of the study sample. Additional construct validation was performed and is avail- able from the authors on request.

Commitment. Affective commitment was measured using a six-item scale from Mowday et al. (1979), which obtained a reliability of $\alpha=.91$. Typical scale items were, "I am proud to tell others that I am part of this hotel," "I care about the fate of this hotel," and "This hotel inspires me to do my best."

$D S B$. We measured DSB using a scale based on the conceptual work by Blancero and Johnson (1997). As with most organizational citizenship behaviors, DSB represents a set of highly socially desirable behaviors (Van Dyne \& LePine, 1998). To minimize the possibility of an inflated measure resulting from self-report, we asked employees to describe the typical behavior of their coworkers and then aggregated these scores. Peer evaluations of citizenship behaviors have been found to be more predictive of performance than are self-evaluations (Van Dyne \& LePine, 1998), and we infer that they are more accurate. This four-item scale asked respondents to indicate the frequency with which they observed the DSBs on the part of coworkers. Typical scale items included, "If one of my coworkers does not know the answer to a guest's question, he or she makes it their business to find out" and "My coworkers go out of their way to accommodate a guest's special request." Respondents indicated whether they had observed these behaviors by other people in their department over the last few months hourly, daily, weekly, monthly, or never. Because employees in different work areas (e.g., front office, housekeeping, restaurant, engineering) are likely to experience different levels of customer contact and therefore have different levels of 
opportunity to exhibit DSBs, individual employee responses were statistically controlled for the respondent's work area and the resulting residuals were aggregated to form the DSB measure. Scale reliabilities performed on item responses after such statistical control yielded $\alpha=.85$. This measure reflects employee perceptions of norms for DSB and is used only in the aggregate form.

Table 2

Descriptive Statistics and Correlation Matrix of all Variables at the Individual Employee Level

\begin{tabular}{lrrrrrrrr}
\hline \multicolumn{1}{c}{ Variable } & $M$ & $S D$ & 1 & 2 & 3 & 4 & 5 & 6 \\
\hline 1. Procedural justice & 3.33 & 0.93 & & & & & \\
2. Interpersonal justice & 3.73 & 0.89 & $.68^{* *}$ & & & & \\
3. Satisfaction with supervision & 3.79 & 0.95 & $.54^{* *}$ & $.62^{* *}$ & & & \\
4. Affective commitment & 3.90 & 0.83 & $.56^{* *}$ & $.57^{* *}$ & $.58^{* *}$ & & \\
5. Employee intent to remain & -0.02 & 0.77 & $.32^{* *}$ & $.35^{* *}$ & $.39^{* *}$ & $.60^{* *}$ & \\
6. Willingness to say negative & 3.93 & 1.16 & $.17^{* *}$ & $.17^{* *}$ & $.18^{* *}$ & $.21^{* *}$ & $.14^{* *}$ \\
\hline
\end{tabular}

Note. $\quad N=5,511$.

$* * p<.01$.

Guest satisfaction. Guest service satisfaction scores were derived from data collected by the site company from frequent travelers who stayed at the property in question. The company sends out 100 guest satisfaction questionnaires each month for each property and reports an average $75 \%$ response rate. These scores are then tallied into 4-month rolling averages, each of which is based on approximately 300 customer surveys. We combined average scores for 14 items that directly connoted guest perceptions of customer service. Although we did not have access to individual respondent information, a reliability analysis was performed on the 4-month averaged and aggregated items, which showed a reliability of $\alpha=.89$. Sample questions included reports of guest satisfaction with service at check-in, room cleanliness, employees' professional attitude and appearance, responsiveness to needs, and overall perceptions of service received. Although the reliability score for the averaged and aggregated data is undoubtedly inflated, as aggregation often increases interitem correlations (Ostroff, 1992), the alpha of .89 appears high enough to retain confidence in the scales.

Intent to remain with the organization. Employee intent to remain was measured using a scale from Robinson (1996). This four-item scale asked employees to respond to three Likert-type questions about how long the employee intends to remain with the employer, the extent to which they would prefer to work for a different employer, the extent to which they have thought about changing companies, and one binary question ("If you had your way, would you be working for this employer three years from now?"). The reliability of this scale was $\alpha=.76$.

Turnover. Employee turnover was drawn from personnel records and was computed for each hotel property as the total number of voluntary and involuntary terminations between January and June 1999 divided by the total number of employees at the hotel 
property. Hotels that were shut down during the period in question were excluded from this analysis. Data distinguishing voluntary from involuntary turnover were not available.

\section{Analyses}

We first examined the distinction between $\mathrm{IJ}$ and $\mathrm{PJ}$ using exploratory factor analysis (EFA) with oblique rotation to assess item loadings. Given the high-expected intercorrelation between the two justice types, we anticipated that EFA eigenvalues might not be sufficient to warrant extraction of two factors, so we forced the analysis to consider the two factors. We then applied confirmatory factor analysis to assess the improvement of fit between a one-factor solution and a two-factor solution to the pool of justice items.

We conducted structural equation modeling (SEM) by using maximum likelihood estimation (AMOS; Arbuckle, 1999). To address the possible role of common-method effects in our model, we performed latent- variables equation modeling using a method developed and applied by Williams and Anderson (1994). This approach requires the inclusion in the model of items from a conceptually uninvolved latent variable (in this case, willingness to say negative things), on which all survey item responses are permitted to cross-load. In effect, this method simultaneously tests for and statistically controls for common method variance. We applied this form of latent variables SEM at the individual and departmental levels of analysis. This form of latent-variables SEM requires more degrees of freedom than were available for our business-unit-level dataset. Thus, to assess justice's association with business-unit-level outcomes, we used AMOS to perform simple maximum likelihood path analyses. As suggested by Brown and Cudeck (1993) and by Hu and Bentler (1999), we used several fit indexes in combination to provide a more complete assessment of model adequacy. We used the conventional likelihood ratio chi-square test, comparative fix index (CFI), goodness-offit index (GFI), adjusted goodness-of-fit index (AGFI), and the standardized root-meansquared residual (SRMR) to assess overall model adequacy. Hu and Bentler (1999) recommended a combined cutoff criterion for good model fit of CFI > .95 and SRMR < .09 and suggested that small decrements in either indicator can be compensated for by enhancements in the other.

Results

The results of EFA of the justice scale items are shown on Table 1. All items loaded appropriately on their designated construct and did not load substantially on the other construct. A confirmatory factor analysis showed that the model that distinguished IJ from PJ fit the data significantly better than the model that combined the two sets of scale items into a single factor, $\Delta x^{2}(1, N=1,097)=1,106.17, p<.01$. Table 2 shows a correlation matrix, at the individual level of analysis, of the variables studied. It is 
important to note that $\mathrm{PJ}$ and $\mathrm{IJ}$ are intercorrelated at $r=.68$, which is consistent with the meta-analytic findings of Colquitt et al. (2001).

Bliese (2000) argued that the aggregation of constructs measured at the individual level should be assessed by examination of $F$ statistics and intraclass correlation coefficient (ICC) statistics, all of which may be computed from an analysis of variance (ANOVA) of responses and the desired groupings. Of special relevance is the ICC(2) score, which indicates the measurement reliability of the group mean. Also of interest is the $R_{w g}$ statistic developed by James, DeMaree, and Wolf (1984). We assessed the relevant statistics for PJ, IJ, commitment, satisfaction with supervision, DSB, and intent to remain. Table 3 shows aggregation statistics for department-level analysis, and it tells a mixed story. Significant $F$ statistics and acceptable $R_{w g}$ scores support department-level aggregation, but fairly low ICC(1) scores indicate substantial variation across observers within departments. ICC(2) scores take into account the sample size from each department and suggest that the small mean sample from each department $(M=9)$

Table 3

Aggregation Statistics to Department Level

\begin{tabular}{lcccc}
\hline \multicolumn{1}{c}{ Variable } & $F$ & $\mathrm{ICC}(1)$ & $\mathrm{ICC}(2)$ & $R_{\mathrm{wg}}$ (avg) \\
\hline 1. Procedural justice & $1.64^{* * *}$ & .08 & .45 & .68 \\
2. Interpersonal justice & $1.67^{* *}$ & .06 & .36 & .78 \\
3. Satisfaction with supervision & $1.61^{* *}$ & .06 & .38 & .72 \\
4. Affective commitment & $1.88^{* *}$ & .08 & .47 & .88 \\
5. Discretionary service behavior & $1.64^{* *}$ & .03 & .22 & .82 \\
6. Employee intent to remain & $1.81^{* *}$ & .05 & .35 & .78 \\
7. Willingness to say negative & $1.97^{* *}$ & .01 & .11 & .63 \\
\hline
\end{tabular}

Note. $\quad$ ICC $=$ intraclass correlation coefficient; $R_{\mathrm{wg}}=$ within-group interrater reliability; avg $=$ average.

$* * p<.01$.

may not be sufficient to generate confidence in the representativeness of the aggregate score. Table 4 assesses aggregation to the hotel or business-unit level. Again, the $F$ statistics and $R_{w g}$ scores are acceptable. In addition, although the ICC(1) scores are slightly lower than in Table 3, the average sample size per unit $(M=90)$ increases the ICC(2) scores to a more acceptable range of values. 
Table 4

Aggregation Statistics to Business-Unit Level

Variable

1. Procedural justice

2. Interpersonal justice

3. Satisfaction with supervision

4. Affective commitment

5. Discretionary service behavior

6. Employee intent to remain
$F \quad$ ICC(1)

$4.58 * *$

$4.01 * *$

$3.00 * *$

$5.08 * *$

$2.34 * *$

$2.91 * *$
.06

.05

.04

.07

.02

.03
ICC(2) $R_{\mathrm{wg}}(\mathrm{avg})$

.78

.65

.75

.79

.67

.87

.82

.81

Note. $\quad$ ICC $=$ intraclass correlation coefficient; $R_{\mathrm{wg}}=$ within-group interrater reliability; avg $=$ average. $* * p<.01$.

The correlation matrices for aggregate variables are shown in Tables 5 and 6 . It is important to note that most of the perceptual variables are more highly intercorrelated at the aggregate level than at the individual level. This difference is especially marked under aggregation to the hotel or business-unit level of analysis. Also, guest reports of service satisfaction were significantly correlated with employee reports of PJ, IJ, employee affective commitment, and DSB.

The results of individual-level latent variables SEM with method controls are shown in Figure 2. All path coefficients were significant at the .01 level. The overall model described showed good fit, $x^{2}(205, N=5,511)=2,254.57, p<.01 ;$ GFI $=.95$, AGFI $=$ .93 , CFI $=.96$, and SRMR $=.03$. It is important to note that the significant chi-square statistic is a common result of extremely large samples and, therefore, is not a cause for concern in assessing this model's fit to the data.

Figure 3 shows the results of department-level latent variables SEM with method controls. Department-level analysis permitted the inclusion in the proposed model of the DSB construct, which is measured using items targeted at the department level. All path coefficients were significant at the .01 level. The overall model described showed good fit, $x^{2}(294, N=783)=1,037.62, p<.01 ; \mathrm{GFI}=.91$, AGFI $=.88$, CFI $=.95$, and $\mathrm{SRMR}=.04$. Given the large sample, the significant chi-square statistic is again not a cause for concern in assessing this model's fit to the data.

The results of hotel-level path analysis predicting employee turnover from aggregate scores are shown in Figure 4. All coefficients were significant at the .01 level. This model showed an acceptable fit to the data according to Hu and Bentler's (1999) 
criteria, with $x^{2}(9, N=98)=31.99, p<.01 ; \mathrm{GFI}=.91$, AGFI $=.79$, CFI $=.94$, and SRMR $=.05$. The low AGFI score, however, prompted some reexamination of the model. Examination of modification indexes suggested an additional link from PJ to satisfaction with supervision. Such a link is conceptually justifiable as a representation of employees' tendency to blame supervisors for unjust policies and is supported by empirical findings of Colquitt (2001) and of Korsgaard and Roberson (1995). Addition of this link, as shown in Figure 5, yielded still significant path coefficients and improved the level of model fit to very good, with $x^{2}(8, N=98)=11.01, n s$, GFI $=.97$, AGFI $=$ $.91, \mathrm{CFI}=.99$, and SRMR $=.03$.

The initial results of path analysis predicting guest satisfaction are shown in Figure 6 . All coefficients but one were significant at the .01 level, and the single exception was significant at the .05 level. The model showed very good fit to the data, with $x^{2}(8, N$ 84) 8.61, ns, GFI .97, AGFI .91, CFI 1.00, and SRMR .03.

Table 5

Descriptive Statistics and Correlation Matrix of all Variables at the Department Level

\begin{tabular}{lcccccccc}
\hline \multicolumn{1}{c}{ Variable } & $M$ & $S D$ & 1 & 2 & 3 & 4 & 5 & 6 \\
\hline 1. Procedural justice & 3.42 & .53 & & & & & & \\
2. Interpersonal justice & 3.79 & .51 & $.70^{* *}$ & & & & & \\
3. Satisfaction with supervision & 3.87 & .56 & $.55^{* *}$ & $.58^{* *}$ & & & & \\
4. Affective commitment & 3.97 & .46 & $.63^{* *}$ & $.61^{* *}$ & $.56^{* *}$ & & & \\
5. Employee intent to remain & 0.02 & .41 & $.38^{* *}$ & $.43^{* *}$ & $.40^{* *}$ & $.68^{* *}$ & & \\
6. Discretionary service & 0.01 & .38 & $.21^{* *}$ & $.19^{* *}$ & $.19^{* *}$ & $.26^{* *}$ & $.20^{* *}$ & \\
$\quad$ behavior & & & & & & & & \\
7. Willingness to say negative & 3.98 & .56 & $.24^{* *}$ & $.24^{* *}$ & $.18^{* *}$ & $.27^{* *}$ & $.18^{* *}$ & $.14^{* *}$ \\
\hline
\end{tabular}

Note. $\quad N=783$.

$* * p<.01$.

Discussion

This study examined the effects of aggregated justice perceptions on the organizational outcomes of employee turnover and guest satisfaction. The results of the analyses support aggregation and are consistent with the notion that aggregate justice perceptions affect organization-level outcomes. They further show that such impact is mediated by the hypothesized affective, cognitive, and behavioral mechanisms.

The differences between the various analyses warrant consideration. Note, first, that aggregation increased most of the interconstruct correlations: PJ and IJ scales, for example, were intercorrelated at $r .69$ at the individual level, but this intercorrelation increased to .87 at the business-unit aggregate level. So high an intercorrelation between the two constructs brings into question the viability of the conceptual 
distinction at the aggregate level of analysis. Correlations between justice perceptions and attitudinal outcomes and between commitment and intent to remain increased

Table 6

Descriptive Statistics and Correlation Matrix of all Variables at the Hotel Level

\begin{tabular}{|c|c|c|c|c|c|c|c|c|c|c|}
\hline Variable & M & $S D$ & 1 & 2 & 3 & 4 & 5 & 6 & 7 & 8 \\
\hline 1. Procedural justice & 3.45 & .30 & & & & & & & & \\
\hline 2. Interpersonal justice & 3.82 & .29 & $.84^{* *}$ & & & & & & & \\
\hline 3. Satisfaction with supervision & 3.87 & .28 & $.76^{* *}$ & $.73 * *$ & & & & & & \\
\hline 4. Affective commitment & 3.97 & .28 & $.82 * *$ & $.77^{* *}$ & $.73^{* *}$ & & & & & \\
\hline 5. Employee intent to remain & -0.02 & .20 & $.54^{* *}$ & $.51^{* *}$ & $.54^{* *}$ & $.77^{* *}$ & & & & \\
\hline 6. Discretionary service behavior & 0.00 & .20 & $.34^{* *}$ & $.36^{* *}$ & $39 * *$ & $44^{* *}$ & $38^{* *}$ & & & \\
\hline 7. Employee tumover & - & $23.33^{\mathrm{a}}$ & -.08 & -.03 & -.09 & -.17 & $-.21^{*}$ & -.11 & & \\
\hline 8. Guest service satisfaction & - & $4.17^{\mathrm{a}}$ & $.25 *$ & $.28 * *$ & $.21 *$ & $32 * *$ & .03 & $34^{* *}$ & .03 & \\
\hline
\end{tabular}

Note. $n=111$ for all variables except employee turnover $(n=98)$ and guest service satisfaction $(n=84)$. Dashes indicate that mean employee tumover and guest satisfaction scores were not disclosed because of a confidentiality agreement that specifically prohibits disclosure of these numbers.

${ }^{a}$ Values are percentages.

${ }^{*} p<.05 .{ }^{* *} p<.01$.

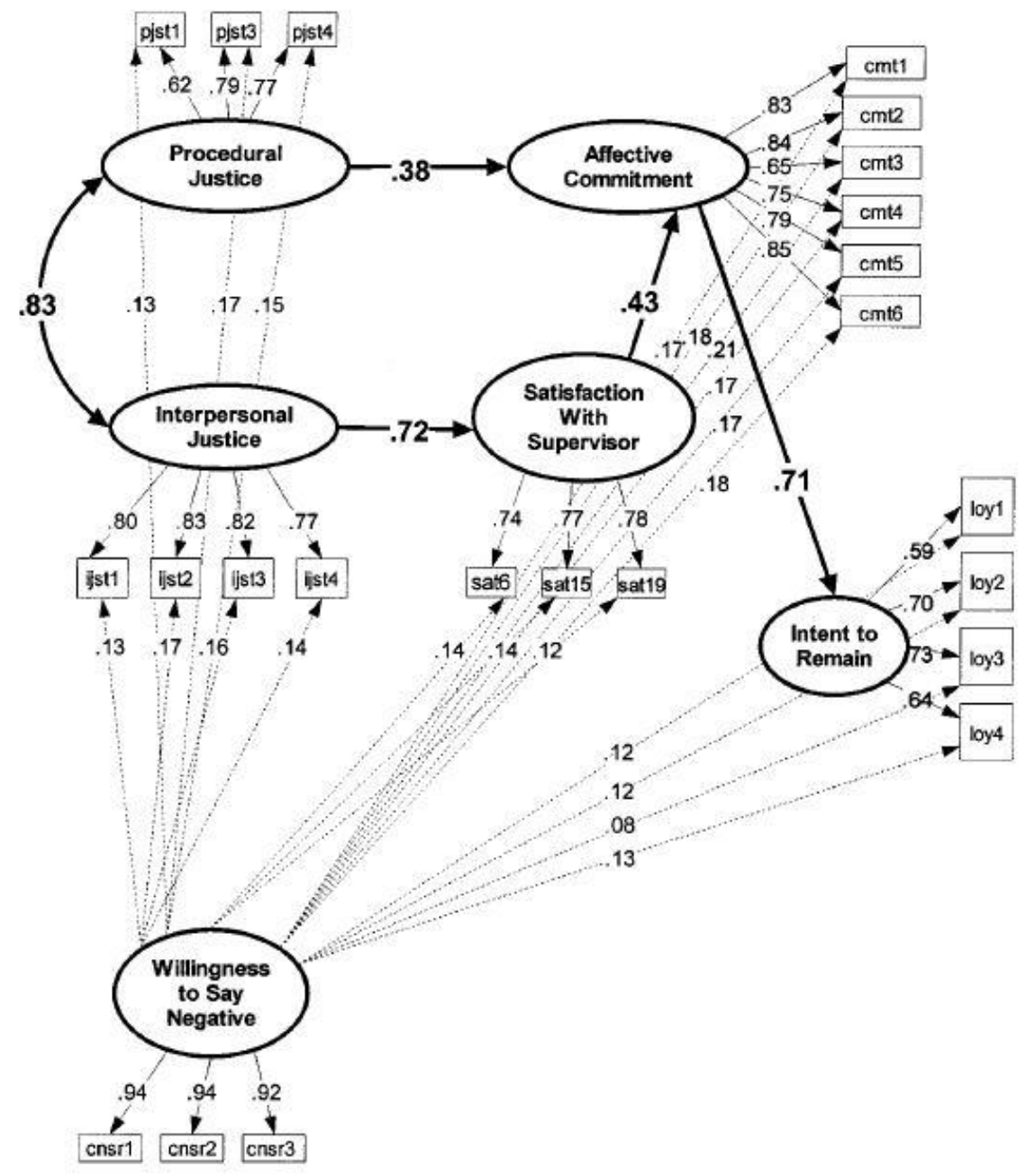

Figure 2. Results of individual-level latent variables structural equation modeling analysis predicting employee intent to remain from justice perceptions, with control for method. $N=5,511$; all paths significant at $p<.01$. pjst $=$ procedural justice $; \mathrm{cmt}=$ commitment loy $=$ loyalty; sat $=$ satisfaction; ijst $=$ interpersonal justice; cnsr $=$ self-censorship . 


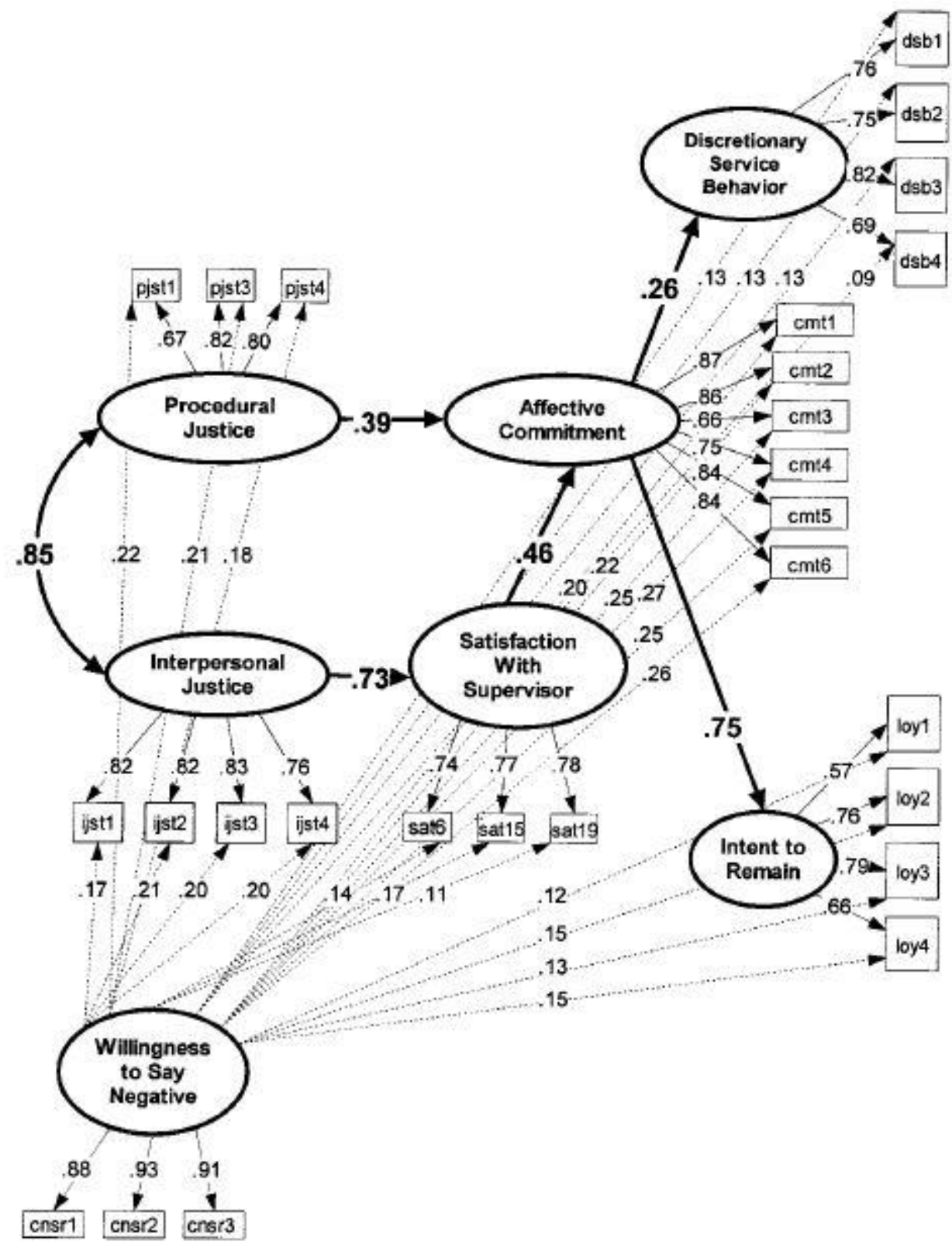

Figure 3. Results of department-level latent variables structural equation modeling analysis predicting employee intent to remain and discretionary service behavior (dsb) from justice perceptions, with control for method. $N=783$; all paths significant at $p<.01$. pjst = procedural justice; $\mathrm{cmt}=$ commitment; loy $=$ loyalty; sat $=$ satisfaction; ijst $=$ interpersonal justice cnsr $=$ self-censorship.

by an average of .10 through the aggregation process. This increase in the strength of links is consistent with the operation of organization-level factors as described by Ostroff (1992).

Different patterns emerged from testing the first part of the model with the two different subsamples of business units, and this difference must be explained. The sample of 98 hotels suggested an unmediated link between PJ and satisfaction with supervision, whereas the smaller subsample of 84 did not. This discrepancy may have 
emerged from one of two sources. First, the initial model depicted in Figure 3 adequately fit the data according to Hu and Bentler's (1999) cutoff criteria and so may not have warranted further modification. Although the CFI of .94 did not attain the desired cutoff value of .95 , the SRMR of .05 substantially exceeds the desired cutoff of .09. Hu and Bentler offered that such tradeoffs are acceptable as indicators of good model fit. This model's low AGFI score of .79, however, mitigates against this possible explanation.

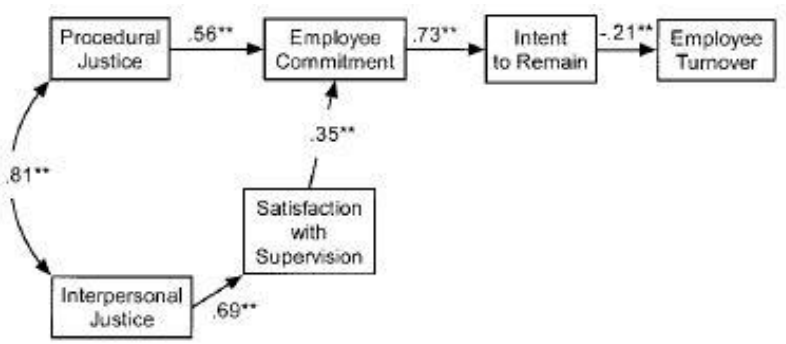

Figure 4. Results of hotel-level path analysis predicting employee turnover from aggregate justice perceptions, initial model. $N=98 .{ }^{* *} p<.01$, one-tailed.

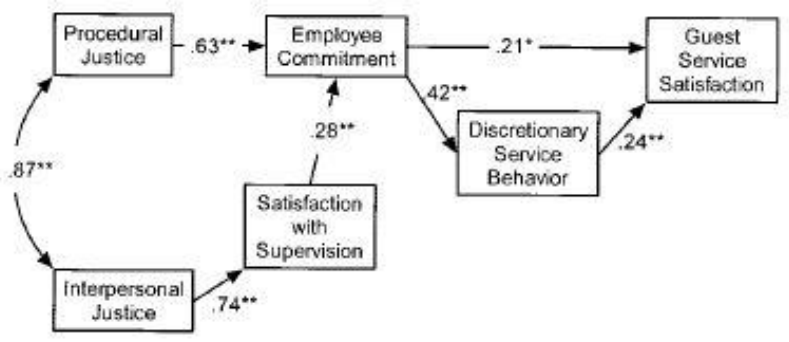

Figure 6. Results of hotel-level path analysis predicting customer service from aggregate justice perceptions. $N=84 .{ }^{*} p<.05 .{ }^{* *} p<.01$, onetailed.

Another possible explanation would rest with the difference between the two samples. The 84 hotels used to test service hypotheses shared a particular franchise, and thus a set of human resources practices, that were not shared among the remainder. Qualitative observation suggests that brand identity was a salient driver of human resource practices (e.g., incentive programs) at the 84 hotels but was less so at the remainder, which held various brand franchises. It is plausible that employees of this hotel chain were less likely to hold supervisors accountable for just or unjust procedures

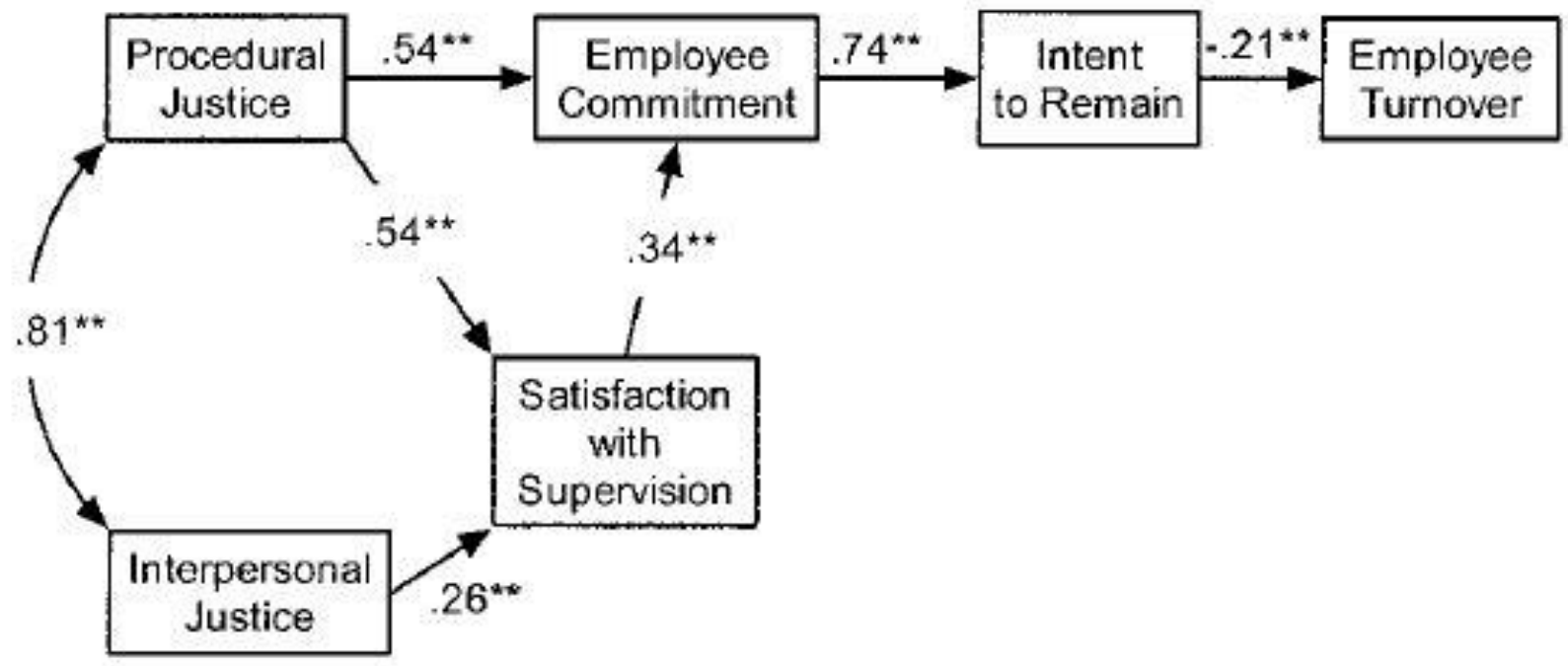

Figure 5. Results of hotel-level path analysis predicting employee turnover from aggregate justice perceptions, final model. $N=98$. ${ }^{*} * p<.01$, one-tailed. 
than were employees at the other hotels, as they could easily credit procedures to the brand. This argument is only very weakly supported by an examination of the relevant correlation matrices: The correlation between PJ and satisfaction with supervision was .74 among the same-branded hotels and was .79 among the remainder. A more dramatic difference, however, emerges from an examination of the association between $\mathrm{PJ}$ and IJ at the two hotel groups: The two justice types are intercorrelated at $r=.87$ for the 84 same-branded hotels, whereas the remaining 27 hotels only show an intercorrelation between the justice types of .73. This difference seems likely to represent a difference in the method of delivering procedural information, or supervising, between the two categories of hotel.

Although Table 6 shows our independent variables as significantly correlated with guest service satisfaction, the low correlations evident between our key independent variables-IJ and PJ - and the dependent variable of employee turnover rates may bring into question the importance and validity of our path analysis. However, the final path analysis yielded standardized indirect effect measures of .09 and .12 for the two justice types, respectively. Furthermore, it must be recalled that the intent of path analysis is the articulation of a sequence of links and that each construct is affected by multiple causes in addition to those measured in the path. In particular, the weakest single link in the articulated chain of impact is between workers' intent to remain and the actual turnover rate, with a raw correlation of only $r=.21$. Although there are certainly multiple causes of employee turnover, especially combined voluntary and involuntary turnover, this last link between intent and action is very well established in the relevant scholarly literature. Our data and analyses, in sum, provide strong evidence in support of our proposed causal chains.

This study has important practical implications for managers. Given the increasing role of the service sector in the modern economy, the results of this study show that fair policies and treatment of employees in organizations may increase an organization's capability to address the needs of its customer base. Fair treatment of employees appears to translate into both employee retention and enhanced customer service, as employees are more committed to the organization and its goals and both employee retention and customer service satisfaction affect profitability (Simons \& McLean Parks, 2000). Interventions aimed at the fairness climate thus seem likely to improve organizational performance. Research supports a trickle-down model of organizational justice in which employee perceptions of fairness are related to their organizational commitment, which influences customer reactions to employees (Masterson, 2001). On the basis of this study, al- lowing greater employee involvement in the design of work procedures or treating employees respectfully and honestly may have "spillover effects" (Bowen, Gilliland, \& Folger, 1999), such that higher levels of employee commitment may lead to more customer-oriented behaviors and, subsequently, customer satisfaction and retention. Second, the results of this study highlight the potential bottom-line impact of organizational justice. Thus, the fair treatment of employees may enhance organizational competitiveness. 
As with any study, there are limitations. First, the data do not represent true longitudinal data and, thus, despite efforts at statistical control, some links may have been influenced by common method variance. Further research using longitudinal data would help to further clarify the effects of fairness on organizational outcomes and the processes by which such outcomes are influenced. Second, because the participant education level was limited, we were required to simplify the survey scales that measure justice perceptions, which may have influenced the relationships between the hypothesized variables. Accordingly, exploring the effects of aggregate justice perceptions among different samples may show more complex relationships between the variables of interest. Future research is needed establish the validity of these results in a variety of organizational contexts and among different employee populations.

Overall, this study makes three key contributions. First, this study builds on Mossholder et al. (1998) by adding empirical support for the validity of aggregate justice perceptions in organizations as a focus for research. Second, the study's results confirm the findings of Masterson et al. (2000) by showing that PJ and IJ are distinguishable and each account for unique variance in out- comes. The third and most unique contribution of this study is that it shows that shared justice perceptions affect organization-level operational outcomes with which managers are concerned and by which manager performance is often measured. As such, it may serve to enhance the visibility and perceived relevance of justice research for managers. 


\section{References}

Arbuckle, J. L. (1999). AMOS 4 (Build 325). Chicago: Smallwaters.

Barling, J., \& Phillips, M. (1993). Interactional, formal and distributive justice in the workplace: An exploratory study. Journal of Psychology, 127, $649-656$.

Bies, R. J. (2000). Interactional (in)justice: The sacred and the profane. In J. Greenberg \& R. Cropanzano (Eds.), Advances in organizational behavior (pp. 89 -118). San Francisco: New Lexington Press.

Bies, R. J., \& Moag, J. F. (1986). Interactional justice: Communication criteria of fairness. In R. J. Lewicki, B. H. Sheppard, \& M. H. Bazerman (Eds.), Research on negotiations in organizations (Vol. 1, pp. 43-55). Greenwich, CT: JAI Press.

Blancero, D., \& Johnson, S. A. (1997, August). Customer service employees and discretionary service behavior: A psychological contract model. Paper presented at the National Conference of the Academy of Man- agement, Boston, MA.

Bliese, P. N. (2000). Within-group agreement, non-independence, and reliability: Implications for data aggregation and analysis. In K. J. Klein \& S. W. J. Kozlowski (Eds.), Multilevel theory, research, and methods in organizations (pp. 349 -382). San Francisco: Jossey-Bass.

Bowen, D. E., Gilliland, S. W., \& Folger, R. (1999). How being fair with employees spills over to customers. Organizational Dynamics, 27, 7-23.

Brockner, J., DeWitt, R. L., Grover, S., \& Reed, T. (1990). When it is especially important to explain why: Factors affecting the relationship between managers' explanations of a layoff and survivors' reactions to the layoff. Journal of Experimental Social Psychology, 26, 389 - 407.

Brown, M. W., \& Cudeck, R. (1993). Alternative ways of assessing model fit. In K. A. Bollen \& J. S. Long (Eds.), Testing structural equation models (pp. $136-162$ ). Newbury Park, CA: Sage.

Cohen, A. (1993). Organizational commitment and turnover: A meta- analysis. Academy of Management Journal, 36, $1140-1157$.

Cohen-Charash, Y., \& Spector, P. E. (2001). The role of justice in organizations: A meta-analysis. Organizational Behavior and Human Decision Processes, 86, 278 321.

Colquitt, J. A. (2001). On the dimensionality of organizational justice: A construct validation of a measure. Journal of Applied Psychology, 86, $386-400$.

Colquitt, J. A., Conlon, D. E., Wesson, M. J., Porter, C. O., \& Ng, K. Y. (2001). Justice at the millenium: A meta-analytic review of 25 years of organizational justice research. Journal of Applied Psychology, 86, 425- 445.

Cropanzano, R., \& Greenberg, J. (1997). Progress in organizational justice: Tunneling through the maze. In C. L. Cooper \& I. T. Robertson (Eds.), International review of industrial and organizational psychology (Vol. 2, pp. 317-372). New York: Wiley.

Greenberg, J. (1990). Organizational justice: Yesterday, today and tomorrow. Journal of Management, 16, $399-432$. 
Greenberg, J. (1993). Stealing in the name of justice: Informational and interpersonal moderators of theft reactions to underpayment inequity. Organizational Behavior and Human Decision Processes, 54, 81-103.

Greenberg, J. (1996). The quest for justice on the job. Thousand Oaks, CA: Sage.

Greenberg, J., \& Lind, E. A. (2000). The pursuit of organizational justice: From conceptualization to implication to application. In C. L. Cooper \& E. A. Locke (Eds.), Industrial/organizational psychology: What we know about theory and practice (pp. 72-107). Oxford, England: Blackwell.

Hosmer, L. T. (1994). Strategic planning as if ethics mattered. Strategic Management Journal, 15, 17-35.

Hu, L.-T., \& Bentler, P. M. (1999). Cutoff criteria for fit indices in covariance structure analysis: Conventional criteria versus new alternatives. Structural Equation Modeling, 6, 1-55.

James, L. R., DeMaree, R. J., \& Wolf, G. (1984). Estimating within-group interrater reliability with and without response bias. Journal of Applied Psychology, 69, 8598.

James, L. R., \& Jones, A. P. (1974). Organizational climate: A review of theory and research. Psychological Bulletin, 81, $1096-1112$.

James, L. R., Joyce, W. F., \& Slocum, J. W., Jr. (1988). Comment: Organizations do not cognize. Academy of Management Review, 13, 129-132.

Jaros, S. J., Jermier, J. M., Koehler, J. W., \& Sincich, T. (1993). Effects of continuance, affective, and moral commitment on the withdrawal process: An evaluation of eight structural equation models. Academy of Management Journal, 36, 951995.

Konovsky, M. (2000). Understanding procedural justice and its impact on business organizations. Journal of Management, 26, $489-511$.

Konovsky, M. A., \& Cropanzano, R. (1991). The perceived fairness of employee drug testing as a predictor of employee attitudes and job performance. Journal of Applied Psychology, 76, $698-707$.

Konovsky, M. A., Folger, R., \& Cropanzano, R. (1987). Relative effects of procedural and distributive justice on employee attitudes. Representative Research in Social Psychology, 17, 15-24.

Korsgaard, M., \& Roberson, L. (1995). Procedural justice in performance evaluation: The role of instrumental and non-instrumental voice in performance appraisal discussions. Journal of Management, 21, 657- 669.

Kozlowski, S. W. J., \& Klein, K. J. (2000). A multilevel approach to theory and research in organizations: Contextual, temporal and emergent processes. In K. J. Klein \& S. W. J. Kozlowski (Eds.), Multilevel theory, research and methods in organizations (pp. 3-91). San Francisco: Jossey-Bass.

Leventhal, G. (1980). What should be done with equity theory? In K. Gergen, M. Greenberg, \& R. Willis (Eds.), Social exchange: Advances on theory and research (pp. 27-55). New York: Plenum Press. 
Lind, E. A., Kray, L., \& Thompson, L. (1998). The social construction of injustice: Fairness judgments in response to own and others unfair treatment by authorities. Organizational Behavior and Human Decision Processes, 75, 1-22.

Lind, E. A., \& Tyler, T. R. (1988). The social psychology of procedural justice. New York: Plenum.

Masterson, S. S. (2001). A trickle-down model of organizational justice: Relating employees' and customers' perceptions of and reactions to fairness. Journal of Applied Psychology, 86, 594-604.

Masterson, S. S., Lewis, K., Goldman, B. M., \& Taylor, M. S. (2000). Integrating justice and social exchange: The differing effects of fair procedures and treatment on work relationships. Academy of Management Journal, 43, 738 -749.

McFarlin, D. B., \& Sweeney, P. D. (1992). Distributive and procedural justice as predictors of satisfaction with personal and organizational outcomes. Academy of Management Journal, 35, 626 - 637.

McLean Parks, J., \& Kidder, D. L. (1994). "Till death do us part..." Changing work relationships in the 1990s. In C. L. Cooper \& D. M. Rousseau (Eds.), Trends in organizational behavior (Vol. 1, pp. 111- 136). New York: Wiley.

Mossholder, K. V., Bennett, N., \& Martin, C. (1998). A multilevel analysis of procedural justice context. Journal of Organizational Behavior, 19, 131-141.

Mowday, R. T., Steers, R. M., \& Porter, L. W. (1979). The measurement of organizational commitment. Journal of Vocational Behavior, 14, 224 -247.

Naumann, S. E., \& Bennett, N. (2000). A case for procedural justice climate: Development and test of a multilevel model. Academy of Management Journal, 43, 881- 889 .

Niehoff, B. P., \& Moorman, R. H. (1993). Justice as a mediator between methods of monitoring and organizational citizenship behavior. Academy of Management Journal, 36, 527-556.

O'Reilly, C., III, \& Chatman, J. (1986). Organizational commitment and psychological attachment: The effects of compliance, identification and internalization on prosocial behavior. Journal of Applied Psychology, 71, 492- 499.

Ostroff, C. (1992). The relationship between satisfaction, attitudes, and performance: An organization-level analysis. Journal of Applied Psychology, 77, 963-974.

Robinson, S. L. (1996). Trust and breach of the psychological contract. Administrative Science Quarterly, 41, $574-599$.

Schminke, M., Ambrose, M. L., \& Cropanzano, R. S. (2000). The effect of organizational structure on perceptions of procedural fairness. Journal of Applied Psychology, $85,294-304$.

Schneider, B. (1987). The people make the place. Personnel Psychology, 40, 437- 453.

Schneider, B., Brief, A. P., \& Guzzo, R. A. (1996). Creating a climate and culture for sustainable organizational change. Organizational Dynamics, 24, 7-19.

Schneider, B., Parkington, J. J., \& Buxton, V. M. (1980). Employee and customer perceptions of service in banks. Administrative Science Quarterly, 25, 252-267.

Schneider, B., \& Reichers, A. E. (1983). On the etiology of climates. Personnel Psychology, 36, $19-39$. 
Scholl, R. W. (1981). Differentiating organizational commitment from expectancy as a motivating force. Academy of Management Review, 6, 589 -599.

Shore, L. M., \& Wayne, S. J. (1993). Commitment and employee behavior: Comparison of affective commitment and continuance commitment with perceived organizational support. Journal of Applied Psychology, 78, 774 -780.

Simons, T., \& McLean Parks, J. (2000, August). The sequential impact of behavioral integrity on trust, commitment, discretionary service behavior, customer satisfaction, and profitability. Paper presented at the National Conference of the Academy of Management, Toronto, Ontario, Canada.

Tett, R. P., \& Meyer, J. P. (1993). Job satisfaction, organizational commitment, turnover intention, and turnover: Path analysis based on meta- analytic findings. Personnel Psychology, 46, 259 -293.

Thibaut, J., \& Walker, L. (1975). Procedural justice: A psychological analysis. Hillsdale, NJ: Erlbaum.

Tyler, T., \& Bies, R. (1990). Beyond formal procedures: The interpersonal context of procedural justice. In J. S. Carroll (Ed.), Applied social psychology and organizational settings (pp. 77-98). Hillsdale, NJ: Erlbaum.

Van Dyne, L., Cummings, L. L., \& McLean Parks, J. (1995). Extra-role behaviors: In pursuit of construct and definitional clarity (a bridge over muddied waters). In L. L. Cummings \& B. Staw (Eds.), Research in organizational behavior (Vol. 17, pp. 215-285). Greenwich, CT: JAI Press.

Van Dyne, L., \& LePine, J. A. (1998). Helping and voice extra-role behaviors: Evidence of construct and predictive validity. Academy of Management Journal, 41, 108 119.

Weiner, Y. (1982). Commitment in organizations: A normative view. Academy of Management Review, 7, $418-428$.

Williams, L. J., \& Anderson, S. E. (1994). An alternative approach to method effects using latent variable models. Journal of Applied Psychology, 79, 323-331.

Zohar, D. (1980). Safety climate in industrial organization: Theoretical and applied implications. Journal of Applied Psychology, 65, 96 -102. 
